Article

\title{
Linearly Polarized UV Light-Induced Optical Anisotropy of PVA Films and Flexible Macrocycle Schiff Base Ni(II), Cu(II), Zn(II) Dinuclear Complexes
}

\author{
Masahiro Takase ${ }^{1}$, Shiomi Yagi ${ }^{1}$, Tomoyuki Haraguchi ${ }^{1}$, Shabana Noor ${ }^{2}$ and \\ Takashiro Akitsu 1,* \\ 1 Department of Chemistry, Faculty of Science, Tokyo University of Science, 1-3 Kagurazaka, Tokyo 162-8601, \\ Japan; h5-1.8-m.t@i.softbank.jp (M.T.); 1317813@ed.tus.ac.jp (S.Y.); haraguchi@rs.tus.ac.jp (T.H.) \\ 2 Department of Applied Sciences and Humanities, Faculty of Engineering and Technology, Jamia Millia \\ Islamia, New Delhi 110025, India; shabanachem0711@gmail.com \\ * Correspondence: akitsu2@rs.tus.ac.jp; Tel.: +81-3-5228-8271
}

Received: 28 November 2018; Accepted: 12 December 2018; Published: 17 December 2018

\begin{abstract}
Three dinuclear metal complexes (comprised of six-coordinated $\mathrm{nNi}_{2} \mathrm{~L}$ and five-coordinated $\mathrm{nCu}_{2} \mathrm{~L}$ and $\mathrm{nZn} \mathrm{n}_{2} \mathrm{~L}$ ) were confirmed by means of elemental analysis, $\mathrm{UV}$-vis and IR spectra, and single $\mathrm{X}$-ray crystal structural analysis in a spectroscopic study. The stable structures of these $\mathrm{nNi}_{2} \mathrm{~L}$, $\mathrm{nCu}_{2} \mathrm{~L}$, and $\mathrm{nZn}_{2} \mathrm{~L}$ complexes in poly(vinylalcohol) (PVA) films were analyzed using UV-vis spectra. The molecular orientation of hybrid PVA film materials after linearly polarized light irradiation was analyzed to obtain the polarized spectra and dichroic ratio. Among the three materials, $\mathrm{nNi}_{2} \mathrm{~L}$ and $n Z n_{2} L$ complexes indicated an increasing optical anisotropy that depended on the flexibility of the complexes. We have included a discussion on the formation of the pseudo-crystallographic symmetry of the components in a soft matter (PVA films).
\end{abstract}

Keywords: Schiff base complex; nickel; copper; zinc; polarized light; poly(vinylalcohol) (PVA); Weigert effect

\section{Introduction}

Organic polymers or liquid crystals, including azo-groups, show optical anisotropy after linearly polarized UV light irradiation, which is the so-called Weigert effect (i.e., polarized light induces optical anisotropy of azo-compounds). It was reported in prior literature [1,2]. To detect such optical anisotropy, polarized absorption UV-vis (electronic) [3] or infrared (IR) [4] spectroscopy was employed previously. Several researchers have investigated hybrid materials for photochromic azo-compounds [5-9], as well as azo-compounds and metal complexes [10], or azo-groups containing metal complexes in various polymer films [11-16]. For such hybrid materials, the chirality of metal complexes or the azo-compounds plays a role in the detection of a separate component of composites [17,18]. In addition, the intermolecular interactions between the components and polymers should also be considered in the discussion on supramolecular chirality and photo-induced molecular arrangement [19]. This concept was developed to investigate matrix proteins using chiral molecular recognition between the protein and (chiral) metal complexes, which were expected to fit both molecular shapes through the rotation of guest molecules by light irradiation [20,21].

Besides the azo-compounds, some components that have a large dipole moment or polarity may be candidates that exhibit light-induced molecular arrangements like the azo-compounds. However, the power to control their alignment may be weaker than in azo-compounds, due to the Weigert effect. Previously, we have attempted to compare some dinuclear complexes with/without 
azo-compounds [22,23]. Such a strategy may be promising to employ various metal complexes more freely than the separated composites of the azo-compounds and metal complexes, when using electronic properties derived from the organic ligand moieties. However, such developments were limited to the molecular-level properties of structures, such as the shape or flexibility of ligands, the expected supramolecular interactions [24], chirality (symmetry), and the tests for "light-induced" supramolecular-level structural properties. For example, crystal symmetry similar to materials in the solid state, has not yet been considered.

In this study, we employed achiral dinuclear Schiff base nickel(II), copper(II), and zinc(II) complexes (hereinafter abbreviated as $\mathrm{nNi}_{2} \mathrm{~L}, \mathrm{nCu}_{2} \mathrm{~L}$, and $\mathrm{nZn}_{2} \mathrm{~L}$, respectively), incorporating the flexibility of macrocyclic ligands and the complexes' hybrid poly(vinylalcohol) (PVA) films, a water-soluble polymer potentially forming hydrogen bonds, without azo-moieties. These hybrid materials were investigated for a molecular and material-level change after UV light irradiation. A previous study was carried out using chiral and rigid dinuclear Schiff base complexes, including azo-dyes in PVA film [23]. For comparison, we explored the achiral symmetry and molecular flexibility of the components' assuming symmetry operations in the crystals at this time.

\section{Materials and Methods}

\subsection{Preparations of the Complexes}

All experiments were carried out in our chemistry laboratory. All the reagents and solvents were of the highest commercial grade available (Aldrich, Wako, or TCI), and were used as received without further purification. As shown in Scheme 1,2,6-dimethylphenol and the complexes were synthesized according to the procedure described in References $[23,25]$, for use in the spectroscopic study after confirming the composition as follows.

$\mathrm{nNi}_{2} \mathrm{~L}$ : Yield: $31.1 \%$. IR (KBr): $1643 \mathrm{~cm}^{-1}$ (s) $(\mathrm{C}=\mathrm{N})$. Anal. Found C; 42.52, H; 3.60, N; 7.64\%. Calcd. C; 42.34, $\mathrm{H} ; 5.33, \mathrm{~N} ; 8.23 \%$ for $\mathrm{C}_{22} \mathrm{H}_{22} \mathrm{Cl}_{2} \mathrm{~N}_{4} \mathrm{Ni}_{2} \mathrm{O}_{2}(\mathrm{MeOH})_{2}\left(\mathrm{H}_{2} \mathrm{O}\right)_{3}$.

$\mathrm{nCu}_{2} \mathrm{~L}$ : Yield: $11.8 \%$. IR $(\mathrm{KBr}): 1639 \mathrm{~cm}^{-1}(\mathrm{~s})(\mathrm{C}=\mathrm{N})$. Anal. Found C; 41.54, H; 3.88, N; $8.81 \%$. Calcd. C; 41.58, $\mathrm{H} ; 4.60, \mathrm{~N} ; 8.82 \%$ for $\mathrm{C}_{22} \mathrm{H}_{22} \mathrm{Cl}_{2} \mathrm{Cu}_{2} \mathrm{~N}_{4} \mathrm{O}_{2}\left(\mathrm{H}_{2} \mathrm{O}\right)_{3.5}$.

nZn ${ }_{2}$ L: Yield: $30.7 \%$ IR $(\mathrm{KBr}): 1638 \mathrm{~cm}^{-1}$ (s) (C=N). Anal. Found C; 40.39, H; 3.50, N; 7.96\%. Calcd. C; 40.24, $\mathrm{H} ; 3.38, \mathrm{~N} ; 8.20 \%$ for $\mathrm{C}_{22} \mathrm{H}_{22} \mathrm{Cl}_{2} \mathrm{~N}_{4} \mathrm{O}_{2} \mathrm{Zn}_{2}\left(\mathrm{CHCl}_{3}\right)_{0.9} \cdot{ }^{1} \mathrm{H}-\mathrm{NMR}$ (DMSO-d6, $300 \mathrm{MHz}$ ): $\delta 1.985$ $(\mathrm{m}, 4 \mathrm{H}), 3.834(\mathrm{~m}, 4 \mathrm{H}), 6.834(\mathrm{t}, 2 \mathrm{H}), 7.535(\mathrm{~d}, 4 \mathrm{H}), 8.384(\mathrm{~d}, 4 \mathrm{H})$.
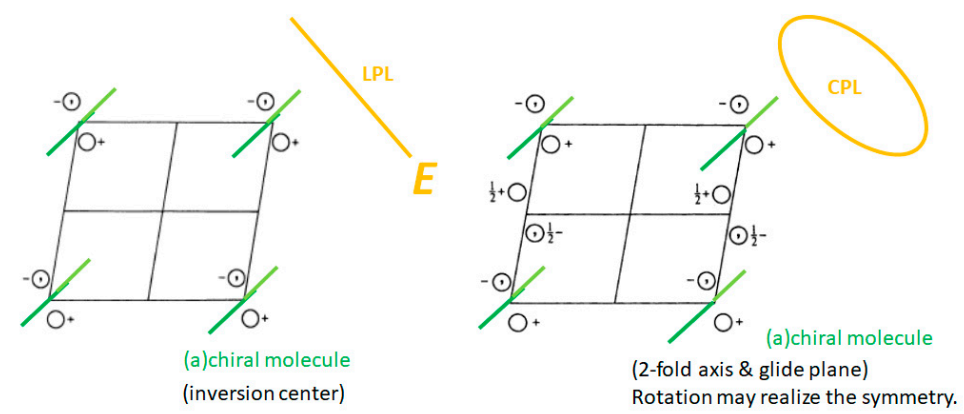

Scheme 1. Concept to induce pseudo-crystallographic symmetry in polymer films using polarized light.

\subsection{Preparation of the PVA Hybrid Cast Films}

Aqueous solutions $(0.5 \mathrm{mM})$ of each complex $\mathrm{nNi}_{2} \mathrm{~L}, \mathrm{nCu}_{2} \mathrm{~L}$, and $\mathrm{nZn}_{2} \mathrm{~L}$, were mixed with PVA $(10 \mathrm{wt} \%)$ and cast onto a slide glass on a hot plate (333 K) for 4 days, to obtain hybrid film materials for the optical experiments.

\subsection{Physical Measurements}

Elemental analyses were carried out with a Perkin-Elmer 2400II CHNS/O analyzer (Perkin-Elmer, Waltham, MA, USA) at the Tokyo University of Science. Infrared (IR) spectra were recorded on a 
JASCO FT-IR 4200 spectrophotometer (JASCO, Tokyo, Japan) in the range between 4000 and $400 \mathrm{~cm}^{-1}$ at $298 \mathrm{~K}$. (Polarized) electronic (UV-vis) spectra were measured on a JASCO V-650 spectrophotometer (JASCO, Tokyo, Japan) equipped with a polarizer in the range between 800 and $220 \mathrm{~nm}$ at $298 \mathrm{~K}$. 1H-NMR spectra were recorded on a JEOL JMN-300 spectrometer (300 MHz) (JEOL, Tokyo, Japan). Fluorescence spectra were measured on a JASCO FP-6200 spectrophotometer (JASCO, Tokyo, Japan) in the range between 720 and $220 \mathrm{~nm}$ at $298 \mathrm{~K}$. Photo-illumination was carried out using a lamp $\left(1.0 \mathrm{~mW} / \mathrm{cm}^{2}\right)$ with optical filters (UV $\lambda=200-400 \mathrm{~nm}$ ), producing a sample using the optical fibers and polarizer through the optical filters.

\subsection{X-ray Crystallography}

Prismatic single crystals were glued onto a glass fiber and coated with a thin layer of epoxy resin to measure the diffraction data. Intensity data were collected on a Bruker APEX2 CCD diffractometer with graphite monochromated Mo K $\alpha$ radiation $(\lambda=0.7107 \AA)$. Data analysis was carried out using the SAINT program package (2012). The structures were solved using direct methods with a SHELXS-97 and expanded by Fourier techniques. The structures were also refined using full-matrix least-squares methods, based on the $F^{2}$ using the SHELXL-97 program [26]. An empirical absorption correction was applied using the SADABS program. All non-hydrogen atoms were readily located and refined using anisotropic thermal parameters. All hydrogen atoms were located at geometrically calculated positions and were refined using riding models.

Crystallographic data for $\mathrm{nNi}_{2} \mathrm{~L}$ (CCDC 1569974, see Supplementary Materials): $\mathrm{C}_{24} \mathrm{H}_{28} \mathrm{Cl}_{2} \mathrm{~N}_{4} \mathrm{Ni}_{2} \mathrm{O}_{4}$, orthorhombic, Pbca, $\mathrm{Z}=4, a=16.4576(10), b=9.3159(6), c=16.5338(10)$ $\AA, V=2534.9(3) \AA^{3}, \rho_{\text {calc }}=1.637 \mathrm{~g} / \mathrm{cm}^{3}, \mu=1.735 \mathrm{~mm}^{-1}, F(000)=1288.0, S=0.859, R_{1}[I>2 \sigma(I)]=$ $0.0332, w R_{2}=0.1090$.

Crystallographic data for $\mathrm{nCu}_{2} \mathrm{~L}$ (CCDC 1569973, see Supplementary Materials): $\mathrm{C}_{22} \mathrm{H}_{32} \mathrm{Cl}_{2} \mathrm{Cu}_{2} \mathrm{~N}_{4} \mathrm{O}_{8}$, monoclinic, $\mathrm{C} 2 / \mathrm{m}, \mathrm{Z}=2, a=7.575(3), b=15.369(7), c=11.708(5) \AA, \beta=$ 93.244(5) $)^{\circ}, V=1360.9(10) \AA^{3}, \rho_{\text {calc }}=1.656 \mathrm{~g} / \mathrm{cm}^{3}, \mu=1.812 \mathrm{~mm}^{-1}, F(000)=696.0, S=1.223, R_{1}[I>$ $2 \sigma(I)]=0.0592, w R_{2}=0.1585$.

Crystallographic data for $\mathrm{nZn}_{2} \mathrm{~L}$ (CCDC 1569972, see Supplementary Materials): $\mathrm{C}_{22} \mathrm{H}_{22} \mathrm{Cl}_{2} \mathrm{~N}_{4} \mathrm{O}_{2} \mathrm{Zn}_{2}$, monoclinic, $C \mathrm{c}, \mathrm{Z}=4, a=16.571(3), b=28.098(3), c=20.346(2) \AA, \beta=$ $103.374(2)^{\circ}, V=9216(2) \AA^{3}, \rho_{\text {calc }}=1.661 \mathrm{~g} / \mathrm{cm}^{3}, \mu=2.347 \mathrm{~mm}^{-1}, F(000)=4672, S=1.848, R_{1}[I>2 \sigma(I)]$ $=0.0536, w R_{2}=0.1015$.

\section{Results and Discussion}

\subsection{Structural Characterization}

Figures 1-3 exhibit the crystal structures of the $\mathrm{nNi}_{2} \mathrm{~L}, \mathrm{nCu}_{2} \mathrm{~L}$, and $\mathrm{nZn}_{2} \mathrm{~L}$, respectively, confirming the axial ligands and chirality around the asymmetric carbon atoms. No remarkable geometrical values were found in the covalent bonds of the ligands [25].

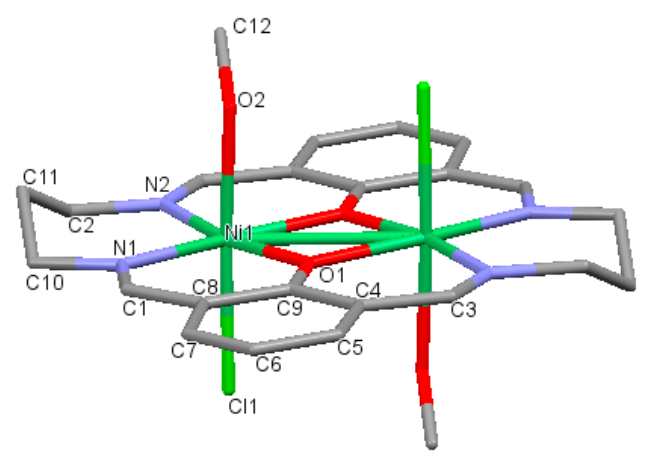

(i)

Figure 1. Cont. 


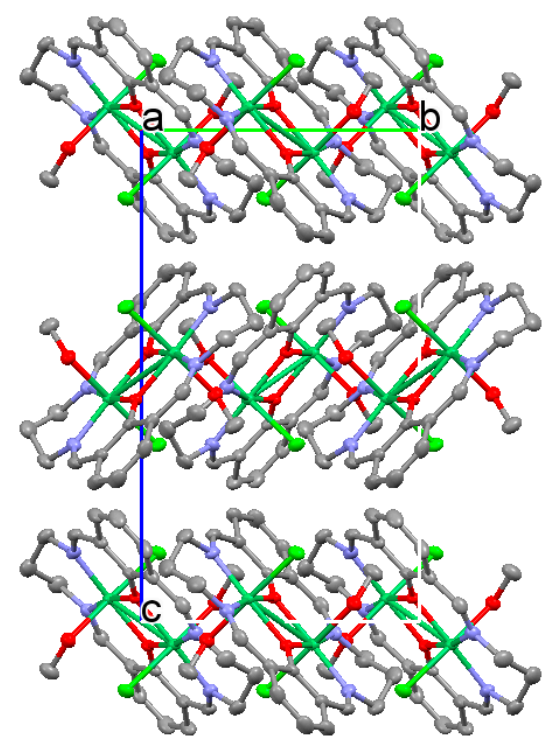

(ii)

Figure 1. (i) Crystal structures of $\mathrm{nNi}_{2} \mathrm{~L}$ showing the atom labeling schemes. Hydrogen atoms and crystalline water were omitted for clarity. (ii) Crystal packing viewed from the crystallographic $a$ axis. $\mathrm{Ni}(1)-\mathrm{Cl}(1)=2.4267(8) \AA, \mathrm{Ni}(1)-\mathrm{O}(1)=2.042(2) \AA$.

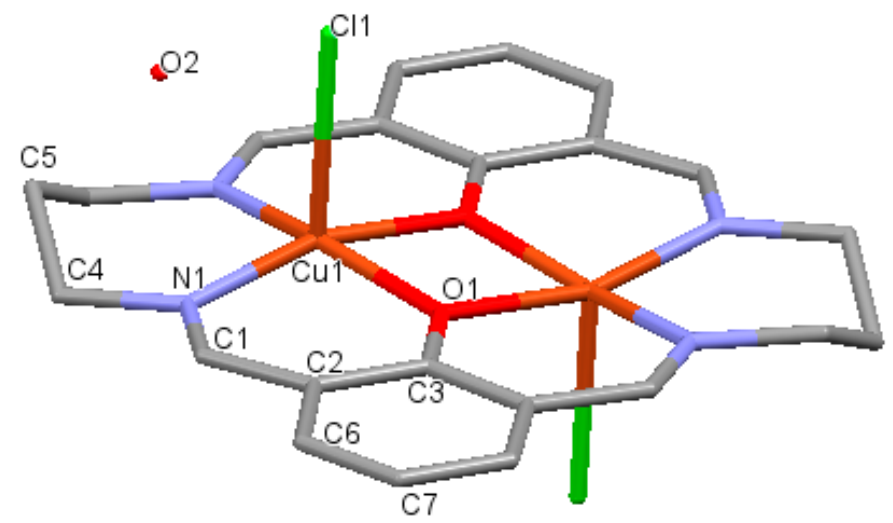

(i)

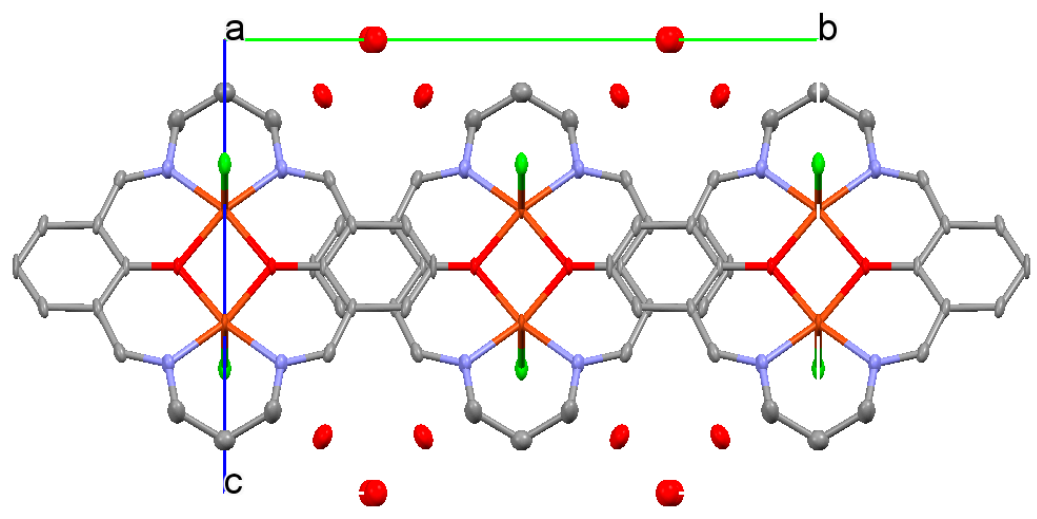

(ii)

Figure 2. (i) Crystal structures of $\mathrm{nCu}_{2} \mathrm{~L}$ showing the atom labeling schemes. Hydrogen atoms were omitted for clarity. (ii) Crystal packing viewed from the crystallographic $a$ axis. $\mathrm{Cu}(1)-\mathrm{Cl}(1)=$ 2.588(13) Å. 


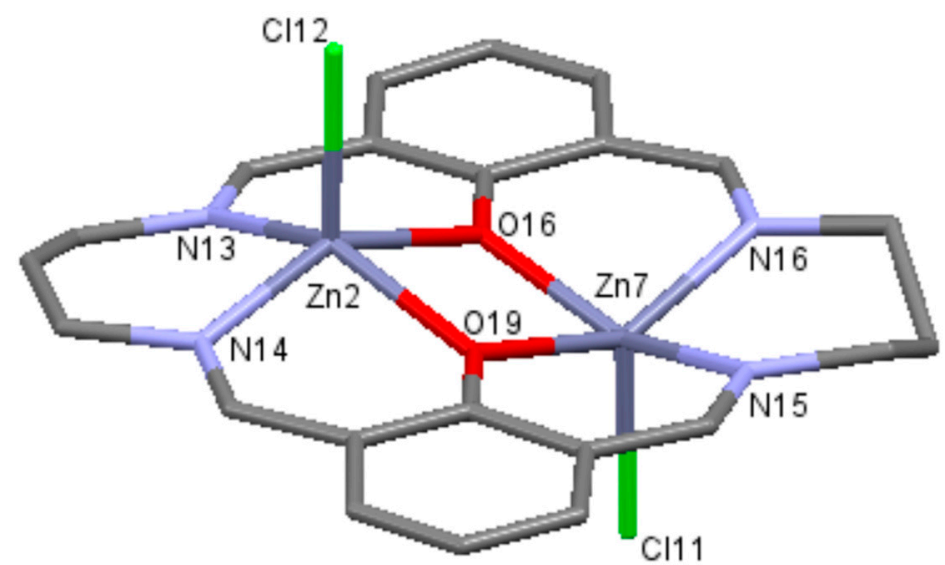

(i)

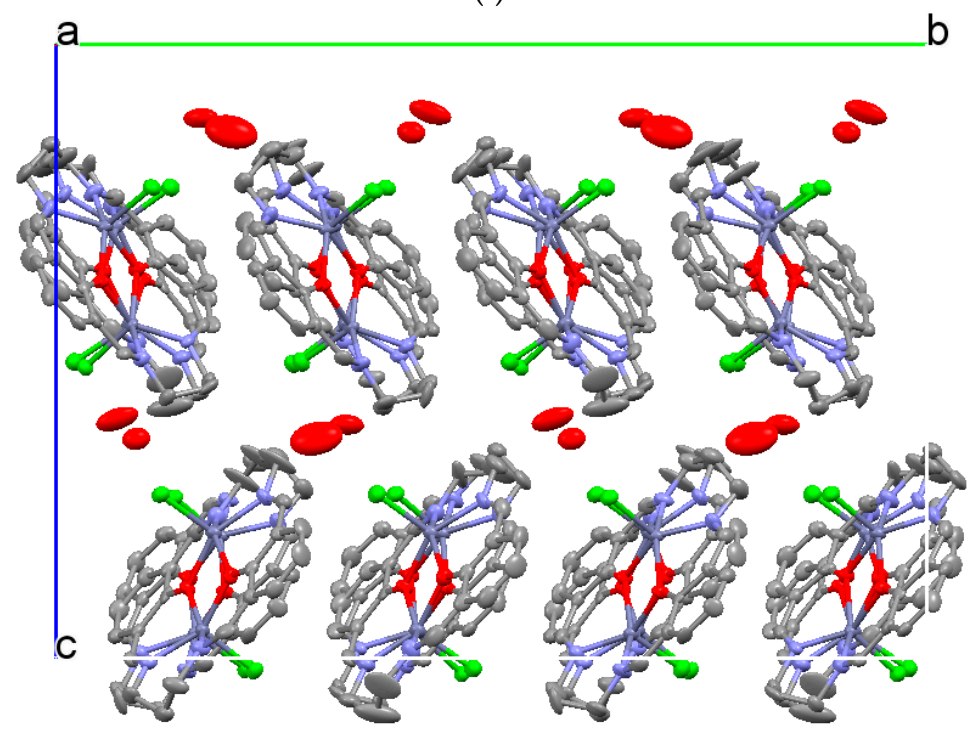

(ii)

Figure 3. (i) Crystal structures of $n Z n_{2} L$ showing the atom labeling schemes. Hydrogen atoms and crystalline water were omitted for clarity. (ii) Crystal packing viewed from the crystallographic $a$ axis. $\mathrm{Zn}(7)-\mathrm{Cl}(11)=2.296(2) \AA, \mathrm{Zn}(2)-\mathrm{Cl}(12)=2.297(3) \AA$.

\subsection{Spectral Characterization}

The IR spectra of all the three complexes $\mathrm{nNi}_{2} \mathrm{~L}, \mathrm{nCu}_{2} \mathrm{~L}$, and $\mathrm{nZn}_{2} \mathrm{~L}$ showed a strong band of 1643 , 1639 , and $1648 \mathrm{~cm}^{-1}$, respectively, which was assignable to the $v(\mathrm{C}=\mathrm{N})$ stretching frequency of the iminic bond present in the complex moiety [27].

UV-Visible (electronic) spectra of all the complexes in solid state, aqueous solution, and PVA were estimated and are shown in Figure 4. It was clear from these spectra that all the metal complexes showed similar structures, as the UV-vis spectra in the PVA were similar to those in the aqueous solution.

For the $\mathrm{nZn}_{2} \mathrm{~L}$, we measured the corresponding UV-vis spectra after UV light ( 360 and $420 \mathrm{~nm}$ ) irradiation for $5 \mathrm{~min}$ (Figure 5, right), as well as the luminescence spectra excited by UV light in an aqueous solution (Figure 5 , left). Absorbance of the UV-vis spectra for the $\mathrm{nZn}_{2} \mathrm{~L}$ aqueous solution decreased by UV light, suggesting that the electronic state of the $\mathrm{nZn}_{2} \mathrm{~L}$ had changed into the excited state. 

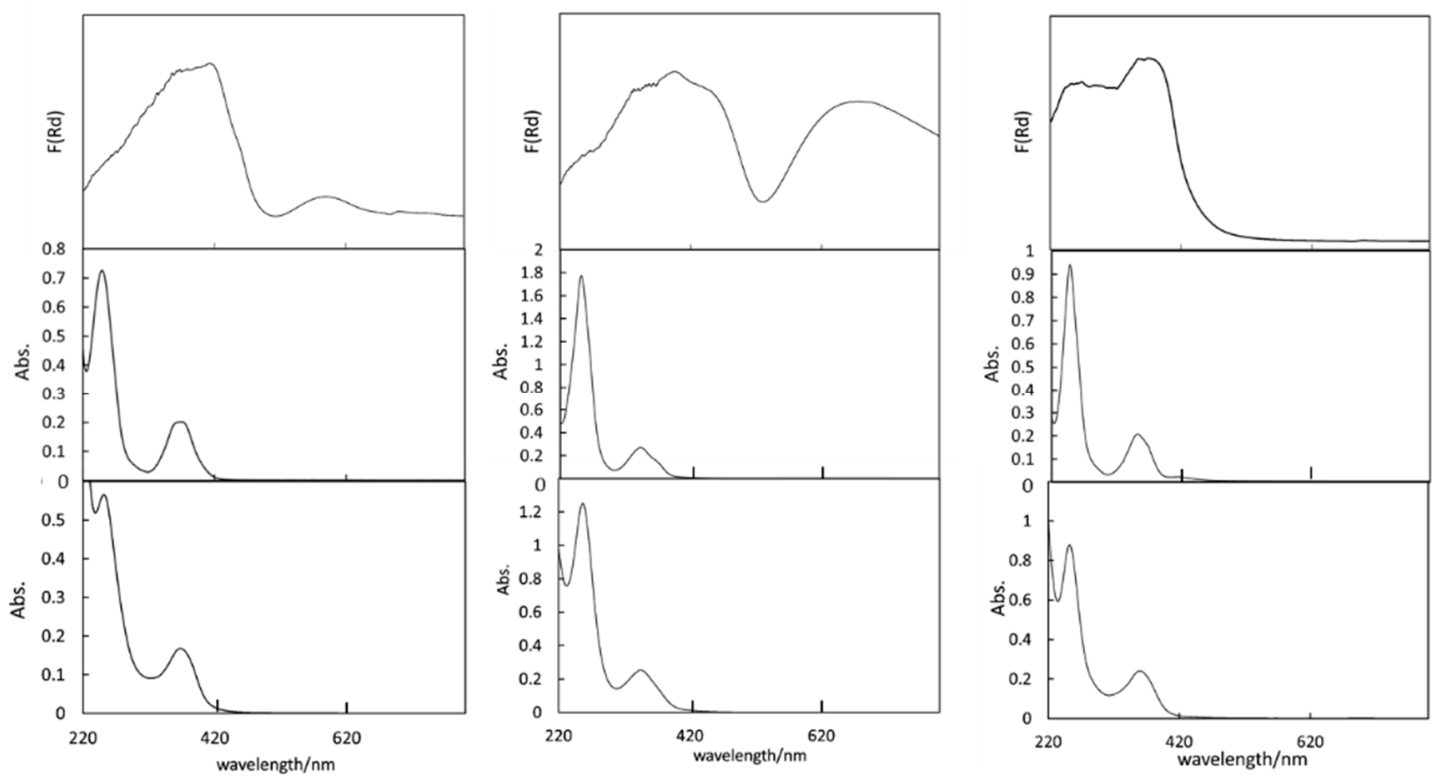

Figure 4. UV-vis spectra of the $\mathrm{nNi}_{2} \mathrm{~L}, \mathrm{nCu}_{2} \mathrm{~L}$, and $\mathrm{nZn}_{2} \mathrm{~L}$ (left, center, right) in the solid state, aqueous solution, and PVA (top, middle, bottom).
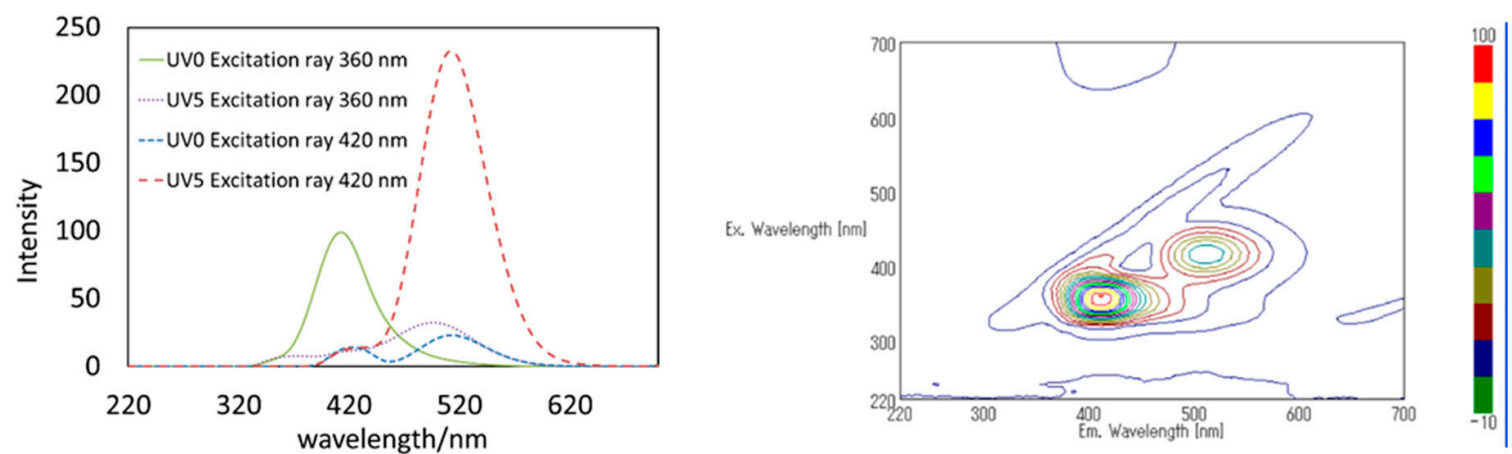

Figure 5. UV-vis spectra and $3 \mathrm{D}$ luminescence spectra for $n Z n_{2} L$ in aqueous solutions under UV light irradiation.

\subsection{Polarized Light Induced-Anisotropic Molecular Orientation}

Prior to the photochemical experiments of the hybrid film materials, we investigated the free volume to rotate molecules in a PVA matrix, the stability against UV light, and the Weigert effect, like the molecular alignment of the complexes in a PVA matrix induced by linearly polarized UV-light (during or after heating to dry to form films), as described in References $[27,28]$. For example, we attempted to irradiate linearly polarized UV light on $\mathrm{nZn}_{2} \mathrm{~L}+\mathrm{PVA}$ for $10 \mathrm{~min}$, and we measured fine changes in the polarized photoluminescence (PL) spectra equipped with an angular polarizer from 0 to 90 degrees [29]. We also obtained linear dichroism by means of polarized UV-vis spectra before and after linearly polarized UV light. Intensity at 0 degrees was larger than that at 90 degrees, suggesting that $\mathrm{nZ} \mathrm{n}_{2} \mathrm{~L}$ changed its molecular orientation similar to the Weigert effect, and it kept a stable chemical species.

Linearly polarized UV-light-induced optical anisotropy in PVA hybrid cast films was successfully observed for the $\mathrm{nNi}_{2} \mathrm{~L}+\mathrm{PVA}$ and $\mathrm{nZn}_{2} \mathrm{~L}+\mathrm{PVA}$, although $\mathrm{nCu}_{2} \mathrm{~L}+\mathrm{PVA}$ did not exhibit clear dichroism. The polarized electronic spectrum of the hybrid materials: $\mathrm{nNi}_{2} \mathrm{~L}+\mathrm{PVA}, \mathrm{nCu}_{2} \mathrm{~L}+\mathrm{PVA}$, and $\mathrm{nZn_{2 }} \mathrm{L}$ + PVA, for every 5 degrees after irradiation with polarized UV light (200-400 nm), was recorded as shown in Figures 6-8, respectively, and summarized in Table 1, with the $R$ and $S$ values for the degree 
of optical anisotropy. The degree of photoinduced optical anisotropy of spectra is described by the $S$ and $R$ parameters, as in Reference [30]:

$$
\begin{gathered}
S=\left(A_{\text {parallel }}-A_{\text {perpendicular }}\right) /\left(2 A_{\text {perpendicular }}+A_{\text {parallel }}\right) \\
R=A_{\text {parallel }} / A_{\text {perpendicular }}
\end{gathered}
$$

where $A_{\text {perpendicular }}$ and $A_{\text {parallel }}$ values denote the absorbance measured by the measuring polarizers that are perpendicular or parallel to the electric vector of irradiation polarized light. Thus, $S=0$ and $R=1$, and both the $S$ and $R$ parameters change with increasing anisotropic molecular orientation due to dichroism.

The $\mathrm{nNi}_{2} \mathrm{~L}+\mathrm{PVA}$ and $\mathrm{nZn} \mathrm{n}_{2} \mathrm{~L}+$ PVA hybrid materials exhibited optical anisotropy in the charge transfer (CT) band (associated with the coordination environment), as well as in the $\pi-\pi^{*}$ band (associated with the organic ligand) after irradiation with the linearly polarized light. This suggested that the transition electric dipole moment was orientated parallel to the linearly polarized light (Figures 6-8). Typically, the $R$ value $0.967 \rightarrow 0.913$ of the CT band of $\mathrm{nNi}_{2} \mathrm{~L}+\mathrm{PVA}$ increased with the anisotropic alignment in the films. This indicated the rigid $\mathrm{nNi}_{2} \mathrm{~L}$ and $\mathrm{nZn}_{2} \mathrm{~L}$ orientation of the dipole moment induced by linearly polarized light. However, the flexible $\mathrm{nCu}_{2} \mathrm{~L}$ did not exhibit optical anisotropy, suggesting that the orientation of the metal complex did not depend on the flexibility (hardness) of the structure around the metal in a complex [25].

Table 1. The $R$ and $S$ values at the $\pi-\pi^{*}$ and CT bands for the composite with PVA after linearly polarized UV light irradiation.

\begin{tabular}{cccccc}
\hline & $\boldsymbol{t} / \mathbf{m i n}$ & $\boldsymbol{R}\left(\boldsymbol{\pi}-\boldsymbol{\pi}^{*}\right)$ & $\boldsymbol{S}\left(\boldsymbol{\pi}-\boldsymbol{\pi}^{*}\right)$ & $\boldsymbol{R}(\mathbf{C T})$ & $S(\mathbf{C T})$ \\
\hline $\mathbf{n N i}_{\mathbf{2}} \mathbf{L}+\mathbf{P V A}$ & 0 & 0.9940 & -0.0020 & 0.998 & -0.0015 \\
& 5 & 0.9929 & -0.0024 & 1.005 & 0.0016 \\
& 10 & 0.9951 & -0.0016 & 1.013 & 0.0042 \\
\hline $\mathbf{n C u}_{\mathbf{2}} \mathbf{L}+\mathbf{P V A}$ & 0 & 0.9845 & -0.00518 & 0.9855 & -0.0049 \\
& 5 & 0.9870 & -0.00435 & 0.9990 & -0.00032 \\
& 10 & 0.9876 & -0.00414 & 1.001 & 0.00032 \\
\hline $\mathbf{n Z n}_{\mathbf{2}} \mathbf{L}+\mathbf{P V A}$ & 0 & 1.007 & 0.0023 & 1.010 & 0.0033 \\
& 0.5 & 1.003 & 0.0011 & 1.108 & 0.0346 \\
& 1 & 0.9247 & -0.0258 & 1.018 & 0.0061 \\
& 3 & 0.9135 & -0.0297 & 1.008 & 0.0026 \\
& 5 & 0.9209 & -0.0271 & 0.9935 & -0.0022 \\
& 10 & 0.9826 & -0.0058 & 1.060 & 0.0196 \\
\hline
\end{tabular}
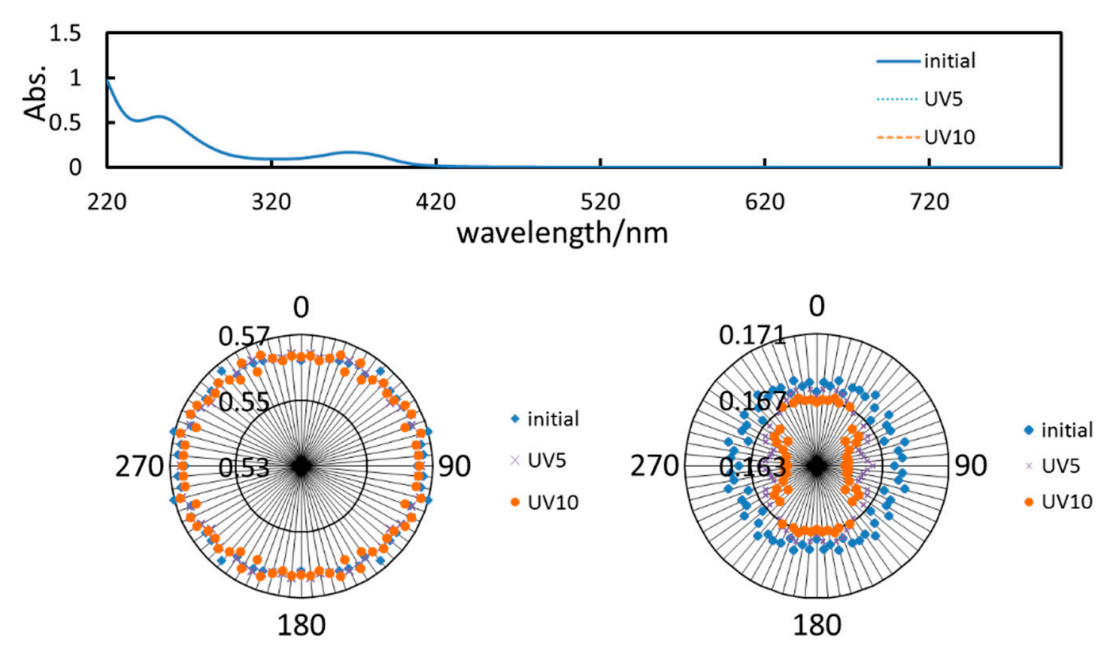

Figure 6. Polarized electronic spectra for $\mathrm{nNi}_{2} \mathrm{~L}+\mathrm{PVA}$ after linearly polarized UV light irradiation (min). Polarizer angle depends on the absorbance of electronic spectra in the $\pi-\pi^{*}$ (left) and CT (right) bands for $\mathrm{nNi}_{2} \mathrm{~L}+$ PVA after linearly polarized UV light irradiation. 


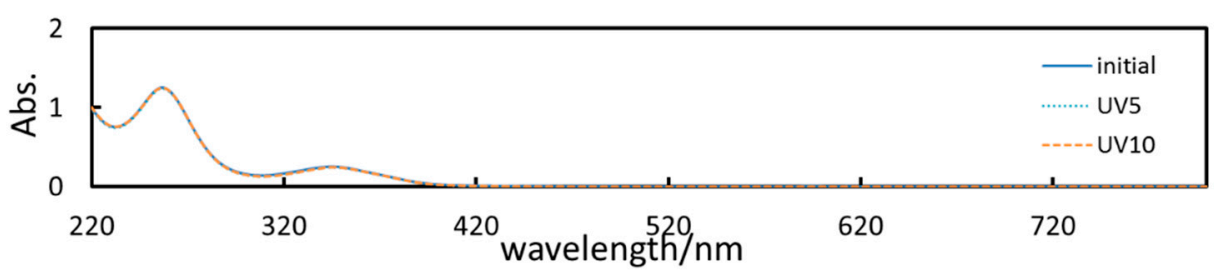

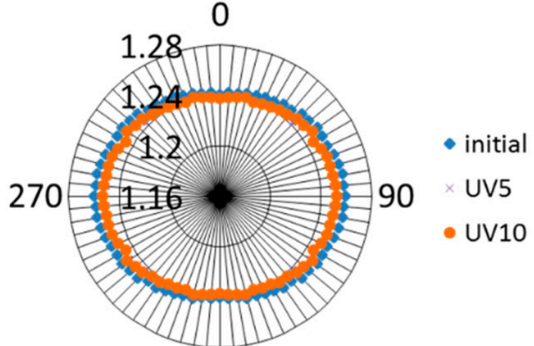

180

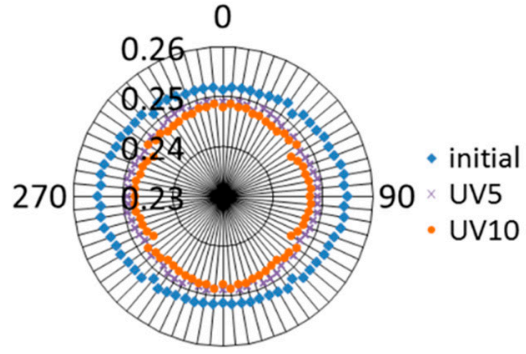

180

Figure 7. Polarized electronic spectra for $\mathrm{nCu}_{2} \mathrm{~L}+$ PVA after linearly polarized UV light irradiation (min). Polarizer angle depends on the absorbance of electronic spectra in the $\pi-\pi^{*}$ (left) and CT (right) bands for $\mathrm{nCu}_{2} \mathrm{~L}+$ PVA after linearly polarized UV light irradiation.

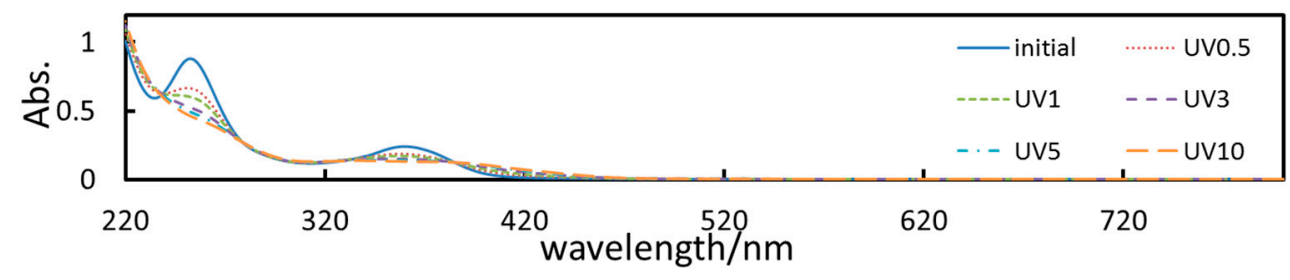

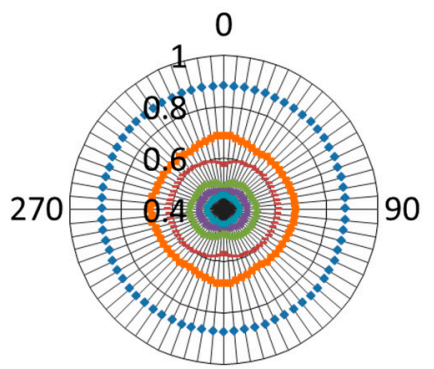

180

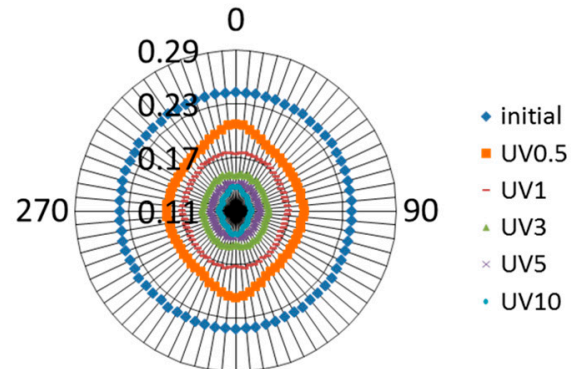

180

Figure 8. Polarized electronic spectra for $n Z n_{2} L+P V A$ after linearly polarized UV light irradiation (min). Polarizer angle depends on the absorbance of electronic spectra in the $\pi-\pi^{*}$ (left) and CT (right) bands for $\mathrm{nZn} \mathrm{n}_{2} \mathrm{~L}+$ PVA after linearly polarized UV light irradiation.

\subsection{Making Pseudo-Crystallographic Symmetry}

However, like the crystalline state, we also successfully induced anisotropic molecular orientation in the PVA films' using linearly polarized UV light irradiation. Recently, the alignment controls of molecules and nanoparticles have been studied to give photo properties [31]. X-ray diffraction spots were obtained, if possible, and the molecular structure was determined in the case of limited conditions [32].

To form symmetry elements like crystals with polarized light in the polymer films (Scheme 1), the intermolecular interactions in chiral crystals of achiral molecules forming screw axes were used as a reference. To form a two-fold screw axis in the crystals, we considered the Weigert effect associated with azobenzene and linearly polarized light originally (and applied circularly polarized light for helical alignments) [33]. For example, it is necessary in finding a new chiral crystallization of compounds containing azobenzene moiety, or at least in finding a new chiral crystallization of achiral compounds 
without azobenzene moiety. New examples of chiral crystallization $\left(P 2_{1}\right)$ were proposed to observe: (1) An azo-organic compound with a long $\pi$-conjugated system, and (2) a five-membered ring with aromaticity. In both crystals, the component molecules were helically connected along one axis by hydrogen bonds.

Moreover, extracting intermolecular interactions from the crystal structure analysis of (a)chiral crystals may be important for induction of the anisotropic or helical orientation of molecules (essentially the dipole moments [34]) in polymer films, using polarized UV light irradiation [35,36]. However, due to the possibility of topological control and a lesser requirement for the molecular symmetry of the components (Scheme 2), (polarized UV) light may represent promising external stimuli for the current purpose.

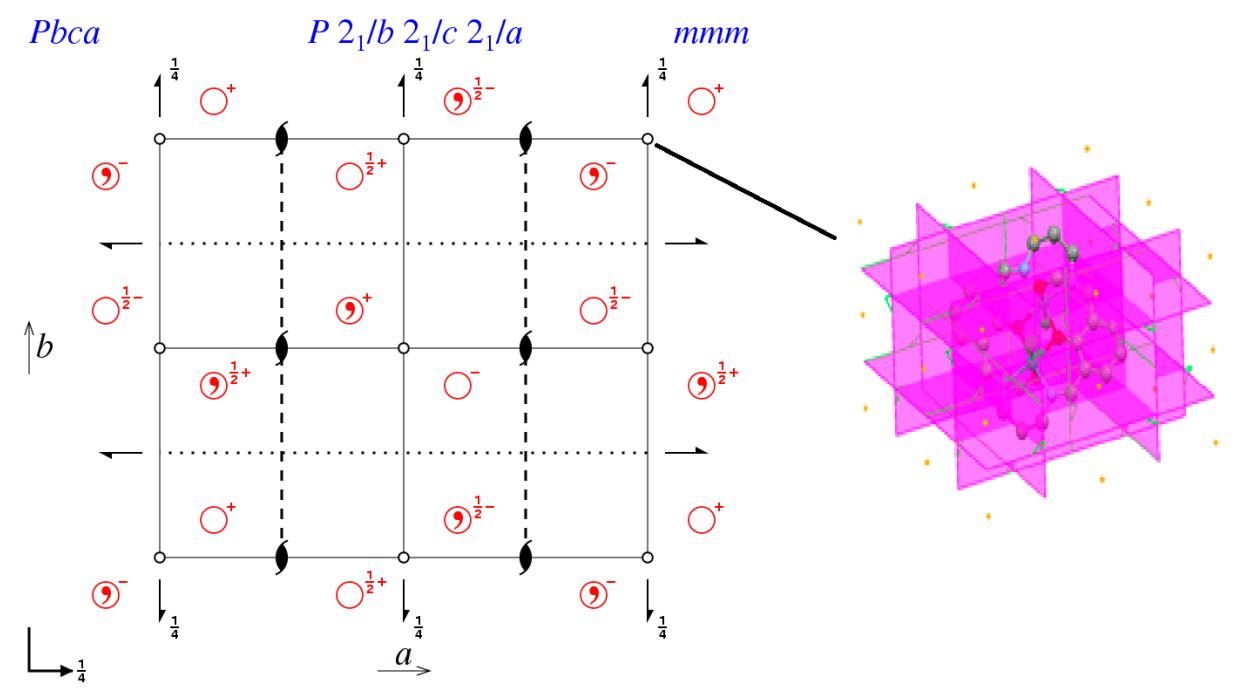

Scheme 2. Molecular symmetry imposed in crystal symmetry. Example for $\mathrm{nNi}_{2} \mathrm{~L}$ in $\mathrm{Pbca}(\# 61)$.

\section{Conclusions}

After linearly polarized UV light irradiation, the optical anisotropy of $\mathrm{nNi}_{2} \mathrm{~L}$ and $n \mathrm{Zn}_{2} \mathrm{~L}$ parallel to the linearly polarized light in PVA was obtained. We attempted to irradiate linearly polarized monochromatic UV light $(360 \mathrm{~nm})$ on $\mathrm{nNi}_{2} \mathrm{~L}+\mathrm{PVA}$, indicating optical anisotropy and molecular orientation. However, this angular optical anisotropy $(R$ value $0.967 \rightarrow 0.913$ ) was vertical to the CT band of the $\mathrm{nNi}_{2} \mathrm{~L}+$ PVA after linearly polarized continuous light irradiation ( $R$ value $0.998 \rightarrow$ 1.013). As a result, we successfully observed linearly polarized UV light-induced molecular orientation, particularly for two materials $\left(\mathrm{nNi}_{2} \mathrm{~L}+\mathrm{PVA}\right.$ and $\left.\mathrm{nZn}_{2} \mathrm{~L}+\mathrm{PVA}\right)$.

Supplementary Materials: The following are available online at http://www.mdpi.com/2073-8994/10/12/ 760 s1. CCDC 1569974, 1569973, and 1569972 contain the supplementary crystallographic data for $\mathrm{nNi}_{2} \mathrm{~L}$, $\mathrm{nCu}_{2} \mathrm{~L}$, and $\mathrm{nZn}_{2} \mathrm{~L}$, respectively. These data can be obtained free of charge via www.ccdc.cam.ac.uk, or from the Cambridge Crystallographic Data Centre, 12 Union Road, CB2 1EZ Cambridge, England, UK; Fax: (+44) 01223 336033; or E-Mail: info@ccdc.cam.ac.uk.

Author Contributions: M.T. and S.Y. performed the experiments; T.H., S.N., and T.A. wrote the paper.

Conflicts of Interest: The authors declare no conflict of interest.

\section{References}

1. Natansohn, A.; Rochon, P. Photoinduced Motions in Azo-Containing Polymers. Chem. Rev. 2002, 102, 4139-4175. [CrossRef] [PubMed]

2. Ichimura, K. Photoalignment of Liquid-Crystal Systems. Chem. Rev. 2000, 100, 1847-1874. [CrossRef] [PubMed] 
3. Norden, B.; Rodger, A.; Dafforn, R. Linear Dichorism and Circular Dichroism A Textbook on Polarized-Light Spectroscopy; RSC Publishing: Cambridge, UK, 2010.

4. Ivanova, B.; Kolev, T. Linearly Polarized IR Spectroscopy Theory and Applications for Structural Analysis; CRC Press: Boca Raton, FL, USA, 2012.

5. Xu, Z.; Shi, L.; Jiang, D.; Cheng, J.; Shao, X.; Li, Z. Azobenzene Modified Imidacloprid Derivatives as Photoswitchable Insecticides: Steering Molecular Activity in a Controllable Manner. Sci. Rep. 2015, 5, 13962. [CrossRef] [PubMed]

6. Wang, L.; Li, Q. Photochromism into nanosystems: Towards lighting up the future nanoworld. Chem. Soc. Rev. 2018, 47, 1044-1097. [CrossRef] [PubMed]

7. Delaire, J.A.; Nakatani, K. Linear and Nonlinear Optical Properties of Photochromic Molecules and Materials. Chem. Rev. 2000, 100, 1817-1845. [CrossRef] [PubMed]

8. Grebenkin, S.; Meshalkin, A.B. Wavelength Dependence of the Reorientation Efficiency of Azo Dyes in polymer Matrixes. J. Phys. Chem. B 2017, 121, 8377-8384. [CrossRef] [PubMed]

9. Statman, D.; Janossy, I. Study of photoisomerization of azo dyes in liquid crystals. J. Chem. Phys. 2003, 118, 3222. [CrossRef]

10. Aritake, Y.; Akitsu, T. The role of chiral dopants in organic/inorganic hybrid materials containing chiral Schiff base $\mathrm{Ni}(\mathrm{II}), \mathrm{Cu}(\mathrm{II})$, and Zn(II) complexes. Polyhedron 2012, 31, 278-284. [CrossRef]

11. Akitsu, T.; Itoh, T. Polarized spectroscopy of hybrid materials of chiral Schiff base cobalt(II), nickel(II), copper(II), and zinc(II) complexes and photochromic azobenzenes in PMMA films. Polyhedron 2010, 29, 477-487. [CrossRef]

12. Akitsu, T.; Ishioka, C.; Itoh, T. Polarized Spectroscopy of Hybrid Materials of Mn12 Single-Molecule Magnet and Azobenzene or Disperse Red 1 in PMMA Films. Cent. Eur. J. Chem. 2009, 7, 690-696.

13. Akitsu, T.; Tanaka, R. Polarized Electronic and IR Spectroscopy of Hybrid Materials of Chiral Cu(II) and Mn12 Complexes and Some Photochromic Compounds in PMMA Films. Asian Chem. Lett. 2010, 14, $235-254$.

14. Akitsu, T.; Tanaka, R. Polarized Electronic and IR Spectra of Hybrid Materials of Chiral Mn(II) Complexes and Different Types of Photochromic Dyes Showing Photoisomerization or Weigert Effect. Curr. Phys. Chem. 2011, 1, 82-89. [CrossRef]

15. Akitsu, T.; Tanaka, R.; Yamazaki, A. Separate observation with polarized electronic and IR spectra of hybrid materials of chiral Mn(II) complexes and azobenzene. J. Mater. Sci. Eng. A 2011, 1, 518-525.

16. Akitsu, T.; Miura, Y. Polarized electronic spectra of organic/inorganic hybrid materials of chiral Schiff base $\mathrm{Ni}(\mathrm{II})$ or $\mathrm{Cu}(\mathrm{II})$ complexes and disperse red 1 or azobenzene in PMMA films. J. Chem. Chem. Eng. 2011, 5, 443-450.

17. Ito, M.; Akitsu, T. Polarized UV light induced molecular arrangement depending on flexibility of chiral Schiff base $\mathrm{Ni}(\mathrm{II}), \mathrm{Cu}(\mathrm{II})$, and $\mathrm{Zn}(\mathrm{II})$ complexes by azobenzene in PMMA matrix. Comtemp. Eng. Sci. 2014, 7, 869-877. [CrossRef]

18. Hariu, N.; Ito, M.; Akitsu, T. Linearly, Circularly, or Non-polarized Light Induced Supramolecular Arrangement of Diastereomer Schiff Base Ni(II), Cu(II), and Zn(II) Complexes by Azobenzene in PMMA Matrix. Comtemp. Eng. Sci. 2015, 8, 57-70. [CrossRef]

19. Aritake, Y.; Takanashi, T.; Yamazaki, A.; Akitsu, T. Polarized spectroscopy and hybrid materials of chiral Schiff base $\mathrm{Ni}(\mathrm{II}), \mathrm{Cu}(\mathrm{II}), \mathrm{Zn}(\mathrm{II})$ complexes with included or separated azo-groups. Polyhedron 2011, 30 , 886-894. [CrossRef]

20. Kominato, C.; Akitsu, T. Photoinduced molecular orientation of catalytic-like chiral azo-Schiff base complexes in PMMA or laccase matrices. Lett. Appl. NanoBioSci. 2015, 2, 264-270.

21. Mitsumoto, Y.; Sunaga, N.; Akitsu, T. Polarized light induced molecular orientation in laccase for chiral azosalenMn(II), $\mathrm{Co}(\mathrm{II}), \mathrm{Ni}(\mathrm{II}), \mathrm{Cu}(\mathrm{II}), \mathrm{Zn}(\mathrm{II})$ mediators toward application for biofuel cell. SciFed J. Chem. Res. 2017, 1, 1 .

22. Tsuda, E.; Mitsumoto, Y.; Takakura, K.; Sunaga, N.; Akitsu, T.; Konomi, T.; Katoh, M. Electrochemical tuning by polarized UV light induced molecular orientation of chiral salen-type $\mathrm{Mn}$ (II) and Co(II) complexes in an albumin matrix. J. Chem. Chem. Eng. 2016, 53-59. [CrossRef]

23. Takase, M.; Akitsu, T. Linearly polarized light-induced anisotropic orientation of binuclear Ni(II), Cu(II), and $\mathrm{Zn}(\mathrm{II})$ Schiff base complexes including or without methyl orange in PVA. In Polymer Science Book Series_Volume \# 1: "Polymer Science: Research Advances, Practical Applications and Educational Aspects"; Formatex Research Centre: Badajoz, Spain, 2016; pp. 301-308. 
24. Takano, H.; Takase, M.; Sunaga, N.; Ito, M.; Akitsu, T. Viscosity and intermolecular interaction of organic/inorganic hybrid systems composed of chiral Schiff base $\mathrm{Ni}(\mathrm{II}), \mathrm{Cu}(\mathrm{II}), \mathrm{Zn}$ (II) complexes having long ligands, azobenzene and PMMA. Inorganics 2016, 4, 20. [CrossRef]

25. Nakatori, H.; Haraguchi, T.; Akitsu, T. Polarized light induced molecular orientation control of rigid Schiff base $\mathrm{Ni}(\mathrm{II}), \mathrm{Cu}(\mathrm{II}), \mathrm{Zn}(\mathrm{II})$ binuclear complexes as polymer composites. Symmetry 2018, 10, 147. [CrossRef]

26. Sheldrick, G.M. A short history of SHELX. Acta Crystallogr. Sect. A 2008, 64, 112-122. [CrossRef] [PubMed]

27. Ito, M.; Akitsu, T.; Palafox, M.A. Theoretical interpretation of polarized light-induced supramolecular orientation on the basis of normal mode analysis of azobenzene as hybrid materials in PMMA with chiral Schiff base Ni(II), Cu(II), and Zn(II) complexes. J. Appl. Solut. Chem. Model. 2016, 5, 30-47.

28. Sekkat, Z.; Dumont, M. Photoinduced orientation of azo dyes in polymeric films. Characterization of molecular angular mobility. Synth. Metals 1993, 54, 373-381. [CrossRef]

29. Moletti, A.; Coluccini, C.; Pasini, D.; Taglietti, A. A chiral probe for the detection of Cu(II) by UV, CD and emission spectroscopies. Dalton Trans. 2007, 1588-1592. [CrossRef] [PubMed]

30. Yamazaki, A.; Akitsu, T. Polarized spectroscopy and polarized UV light-induced molecular orientation of chiral diphenyl Schiff base $\mathrm{Ni}(\mathrm{II})$ and $\mathrm{Cu}(\mathrm{II})$ complexes and azobenzene in a PMMA film. RSC Adv. 2012, 2, 2975-2980. [CrossRef]

31. Beaudoin, E.; Abecassis, B.; Constantin, D.; Degrouard, J.; Davidson, P. Strain-controlled fluorescence polarization in a CdSenanoplatelet-block copolymer composite. Chem. Commun. 2015, 51, 4051-4054. [CrossRef]

32. Ma, H.; Zhu, M.; Luo, W.; Li, W.; Fang, K.; Mou, F.; Guan, J. Free-standing, flexible thermochromic films based on one-dimensional magnetic photonic crystals. J. Mater. Chem. C 2015, 3, 2848-2855. [CrossRef]

33. Schellman, J.; Jensen, H.P. Optical spectroscopy of oriented molecules. Chem. Rev. 1987, 87, 1359-1399. [CrossRef]

34. Sakai, H. Controlling the alignment of neutral molecules by a strong laser field. Friedrich, B.; Herschbach, D. Enhanced orientation of polar molecules by combined electrostatic and nonresonant induced dipole forces. J. Chem. Phys. 1999, 111, 6157.

35. Akitsu, T.; Yamazaki, A.; Kobayashi, K.; Haraguchi, T.; Endo, K. Computational Treatments of Hybrid Dye Materials of Azobenzene and Chiral Schiff Base Metal Complexes. Inorganics 2018, 6, 37. [CrossRef]

36. Van der Asdonk, P.; Kouwer, P.H.J. Liquid crystal templating as an approach to spatially and temporally organise soft matter. Chem. Soc. Rev. 2017, 46, 5935-5949. [CrossRef] [PubMed] 